\title{
A Model for the Analysis of Ultimate Capacity of RC and PC Corroded Beams
}

\author{
Antonino Recupero $\mathbb{D}^{1},{ }^{1}$ Nino Spinella $\mathbb{D},{ }^{1}$ and Francesco Tondolo ${ }^{2}$ \\ ${ }^{1}$ Department of Engineering, Università di Messina, 98166 Sant'Agata, Messina, Italy \\ ${ }^{2}$ Department of Structural, Geotechnical and Building Engineering, Politecnico di Torino, Corso Duca degli Abruzzi 24, \\ 10129 Torino, Italy
}

Correspondence should be addressed to Nino Spinella; nspinella@unime.it

Received 31 January 2018; Revised 28 May 2018; Accepted 21 June 2018; Published 26 July 2018

Academic Editor: Giovanni Garcea

Copyright (c) 2018 Antonino Recupero et al. This is an open access article distributed under the Creative Commons Attribution License, which permits unrestricted use, distribution, and reproduction in any medium, provided the original work is properly cited.

\begin{abstract}
Corrosion of steel in reinforced and prestressed concrete beams is very common for structures and infrastructures. It can drastically reduce the resisting section of rebar, modify the mechanical response of the steel rebar, and also determine cracking of the surrounding concrete because of the volume expansion effect of rust. Moreover, it heavily influences the bond between steel rebar and concrete. Few experimental tests are available in the literature, where the structural behavior of reinforced and prestressed concrete beams, in presence of corrosion of longitudinal and transversal reinforcement, is analyzed. A reduction of the bearing performance is observed with an increasing level of rebar corrosion. Indeed, a changing collapse mechanism is evidenced through the tests and may be addressed to the not obvious consequences of corrosion. In this paper, a physical model based on a consistent equilibrium and ultimate strength theory is employed in order to explain the residual capacity of corroded beams. The model is based on limit analysis, and it is able to take into account the interaction between shear, bending moment, and axial forces.
\end{abstract}

\section{Introduction}

The corrosion damage is actually one of the most problematic issues both for reinforced concrete (RC) and prestressed concrete (PC) structures. It is quite common to have concrete structures affected by corrosion especially if the structures have far exceeded their service lifetime unless the use of special precautions as stainless steel, protective coatings, or nonmetallic reinforcing elements.

This phenomenon may be due to chloride concentrations around the rebar and/or the carbonation of concrete cover for ordinary reinforcement or stress corrosion due to hydrogen embrittlement. The poor grouting of tendons for prestressing steel, other than the presence of specific corrosive chemical agents, can induce the reinforcement cross section loss.

Different issues can be addressed to corrosion of steel reinforcement in concrete: the reduction of the cross section of rebar together with the yielding and ultimate strength level and ductility of steel in the residual cross section, the loss of bond between steel and concrete, and the loss of bearing capacity of cracked concrete around corroding steel, due to the expansion of the oxides, other than as an extreme consequence the spalling and delamination of the cover [1-3]. These effects are responsible for the reduction of the performance of both RC and PC structures in service other than at ultimate conditions.

For RC structures, the corrosion action is evidenced by the rust stains on the external surface of the structure, but this scenario is so common that may be considered normal and so a lack of control is possible. On the contrary, for PC structures, some events of collapse appeared $[4,5]$ without any warning suggesting a much more critical issue.

An extensive literature on the structural behavior of corroded RC elements is available [6-9] and a series of mechanical models using the finite element method (FEM) was developed in order to simulate the effects of this 
degradation mechanism [10-12]. Some experimental researches and models were investigated and developed respectively also for PC structures [13-15], even if for PC structures a systematic study is still not available.

Some advices on the structural response of corroded rebar were summarized by Cairns et al. [16] where a dataset collection was obtained also from previous experimental campaigns. The structural effects were strictly connected to the spatial distribution and the entity of corrosion attack on the bar.

In case of prestressed steel reinforcement, the tendency is to consider the total lack of the strand or wire and to work on the possible bond effect due to the grout [17].

In structures with ordinary reinforcement, the bond strength reduction between steel and concrete, for corrosion levels higher than $1.5 / 2 \%$ of mass loss, can influence the structural behavior, especially in presence of a low amount of confinement. This is the case of existing structures where detailing to enhance ductility and anchorage performance was not completely adequate. In fact, longitudinal cracking caused by corrosion and the progressive loss of confinement exerted by concrete is responsible for a change of behavior for anchorages and overlapping zones and more in general for the transfer mechanism of stresses [16], further exalted if a mechanical action is present [18].

The cracking of concrete, caused by the expansive nature of the oxides, generates a loss of bearing capacity of concrete that could determine negligible effects for tensile zone but substantial impact in compression zone.

The presence of corrosion, generally, reduces the load bearing capacity and ductility of RC beams. Shear strength is affected by corrosion particularly when stirrups reinforcing area is reduced as reported in Kahn et al. [19] and El-Sayed [20] and highlighted in fib bulletin 10 (bond of reinforcement in concrete) [21]. However, in absence of shear reinforcement as for slabs, when corrosion takes place and a substantial change in failure mechanism takes place after longitudinal splitting, an increase in both structural capacity and ductility could be registered [22]. This is mainly due to an arch-tie action that could enhance the structural performance of the RC element.

In general, the consequences of corrosion attacks, other than determining a safety reduction, can bring to a change in failure mechanism passing through ductile (bending) to brittle (shear) [6] just because the stirrups are the most external steel elements and are affected by corrosion penetration before than longitudinal steel (both ordinary or prestressing).

A number of refined FEMs were employed to simulate the experimental tests $[10,13]$. In this scenario, an analytical model able to capture the actual bearing capacity of corroded RC and PC structures, but also the interaction between failure modes, could be useful. Furthermore, considering the scatter of the corrosion phenomena, an analytical model could represent a more effective tool to check the residual strength of large set of elements of structures and infrastructures.

\section{Description of the Theoretical Model}

Many contributions are present in the literature about the interaction between axial force, bending, and shear. They usually are based on the two following different approaches: empirical and theoretical.

The formulations of the first group are founded on a large number of test results carried out on RC members, and they try to provide handy equations for designers.

By contrast, some models, part of the second group, start from the theory of the stress fields and propose formulations that are valid in wide ranges of input parameters, taking into account the interaction between forces (shear, bending moment, and axial force).

In this work, a sectional model belonging to the theoretical group of formulations, originally proposed by Recupero et al. [23], and widely validated [24] against several test results on columns and beams having circular cross section [24] as well as being used for design [25], was adapted to provide the axial force-shear-flexure strength of specimens under corrosion effects. It allows to consider the simultaneous action of bending moment and shear force on the beam, for an assigned value of axial force.

The adopted procedure for the shear-flexure strength evaluation consists of dividing the cross section of the beam into layers of depth $y_{i}$ not known a priori, and subjected to both uniform normal $\sigma_{i}$ and shear $\tau$ stress distributions to ensure the equilibrium with the actions $N, M$, and $V$.

The cross section of the beam was divided into three concrete layers having areas $S_{\mathrm{c} 1}, S_{\mathrm{c} 2}$, and $S_{\mathrm{c} 3}$, while the longitudinal rebars were modeled as point elements grouped into two steel layers (top and bottom), which have areas $S_{\mathrm{s} 1}$ and $S_{\mathrm{s} 2}$, respectively (Figure 1(c)).

With reference to the concrete element in Figure 1(a), obtained by a cut with a plane inclined as the web concrete stress field at the abscissa $z+\Delta z$, the equilibrium equation along the vertical $(y)$ direction can be written as follows:

$$
V^{*}-q \Delta z=V_{\mathrm{Rs}}=\frac{A_{\mathrm{sW}}}{s_{\mathrm{w}}} \sigma_{\mathrm{sw}} y_{3} \cot \theta+A_{\mathrm{p}} \sigma_{\mathrm{p}} \sin \varepsilon,
$$

where $V^{*}$ is the shear force at the abscissa $z ; q$ is the distributed vertical load; $\sigma_{\mathrm{sw}}$ is the axial stress on the steel stirrups; and $A_{\mathrm{p}}, \sigma_{\mathrm{p}}$, and $\varepsilon$ are area, axial stress, and slope, respectively, of the equivalent tendon.

Considering a new column segment obtained by cutting the element with a section plane orthogonal to the beam axis at the abscissa $z$ and $z+\Delta z$ (Figure 1(b)), an equilibrium equation of the piece of beam in the $y$ direction is as follows:

$$
V^{*}-q \Delta z=V_{\mathrm{Rc}}=\sigma_{\mathrm{cw}} S_{\mathrm{c} 3} \cos \theta \sin \theta+A_{\mathrm{p}} \sigma_{\mathrm{p}} \sin \varepsilon,
$$

where $\sigma_{\mathrm{cw}}$ is the concrete stress in the $S_{\mathrm{c} 3}$ region. Furthermore, the equilibrium equations between the internal and the external forces are as follows: 


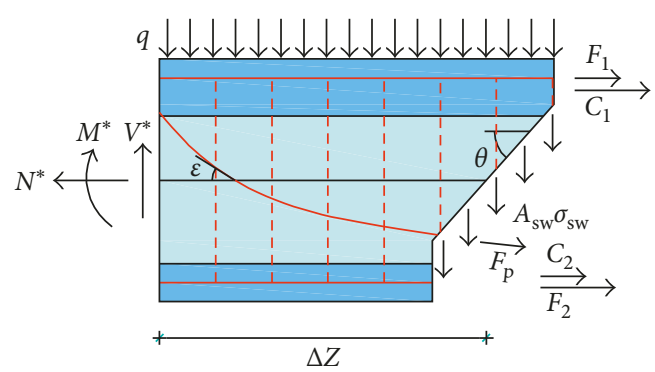

(a)

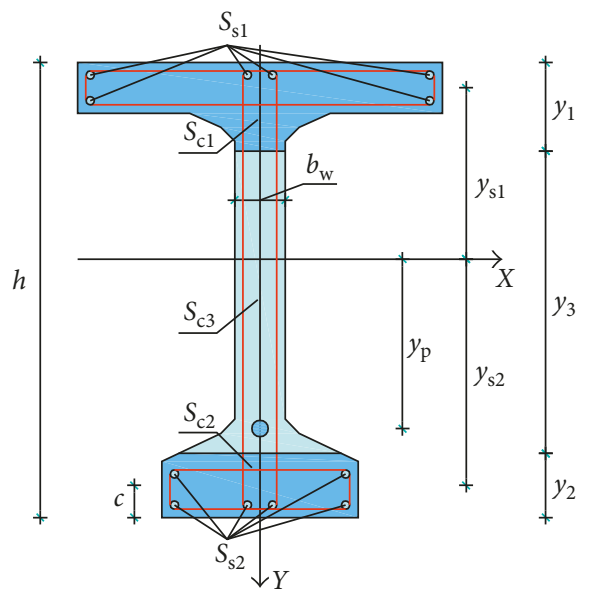

(c)

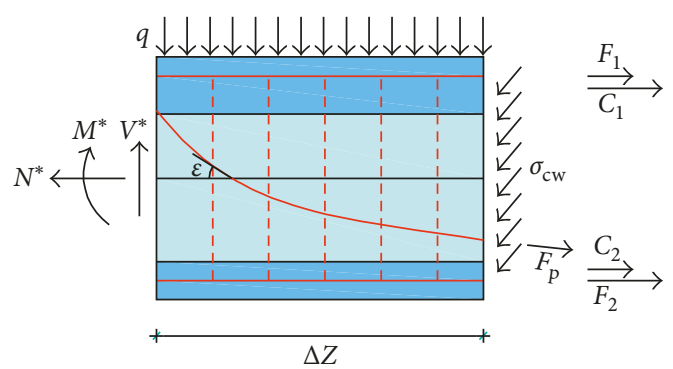

(b)

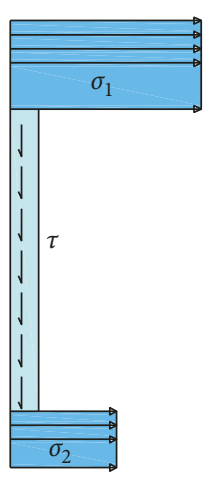

Figure 1: (a, b) External and internal forces scheme assumed; (c) cross-sectional model of the beam.

$$
\begin{aligned}
& \sigma_{\mathrm{c} 1} \int_{S_{\mathrm{c} 1}} d S_{\mathrm{c} 1}+\sigma_{\mathrm{c} 2} \int_{S_{\mathrm{c} 2}} d S_{\mathrm{c} 2}+\left(\sigma_{\mathrm{p} 0}+\Delta \sigma_{\mathrm{p}}\right) A_{\mathrm{p}} \cos \varepsilon+\sigma_{\mathrm{s} 1} A_{\mathrm{s} 1} \\
& +\sigma_{\mathrm{s} 2} A_{\mathrm{s} 2}=C_{1}+C_{2}+F_{\mathrm{p}}+F_{1}+F_{2}=N_{\mathrm{E}}+V_{\mathrm{R}} \cot \theta, \\
& \sigma_{\mathrm{c} 1} \int_{S_{\mathrm{c} 1}} y_{\mathrm{c}} d S_{\mathrm{c} 1}+\sigma_{\mathrm{c} 2} \int_{S_{\mathrm{c} 2}} y_{\mathrm{c}} d S_{\mathrm{c} 2}+\left(\sigma_{\mathrm{p} 0}+\Delta \sigma_{\mathrm{p}}\right) A_{\mathrm{p}} y_{\mathrm{p}} \cos \varepsilon \\
& +\sigma_{\mathrm{s} 1} A_{\mathrm{s} 1} y_{\mathrm{s} 1}+\sigma_{\mathrm{s} 2} A_{\mathrm{s} 2} y_{\mathrm{s} 2}=M_{\mathrm{E}}+V_{\mathrm{R}} \cot \theta\left(\frac{\int_{S_{\mathrm{c} 3}} y_{\mathrm{c}} d S_{\mathrm{c} 3}}{\int_{S_{\mathrm{c} 3}} d S_{\mathrm{c} 3}}\right),
\end{aligned}
$$

where $\sigma_{\mathrm{c} i},\left(\sigma_{\mathrm{p} 0}+\Delta \sigma_{\mathrm{p}}\right)$, and $\sigma_{\mathrm{s} i}$ are the axial stress of the chord concrete, equivalent tendon, and steel rebar related to the $i$ th layer, respectively; $C_{i}, F_{\mathrm{p}}$, and $F_{i}$ the resultant forces in the concrete, equivalent tendon, and the steel rebar related to the $i$ th layer, respectively; and $y_{c}, y_{p}$, and $y_{s i}$ are the lever arms calculated from the centroid of the cross section.

The crisis of the beam may occur either by concrete crushing or by transversal reinforcements yielding. Using the nominal values for the steel yielding $f_{\mathrm{ym}}$ and for the concrete compression strength $f_{\mathrm{cm}}$, the terms related to the areas $S_{\mathrm{c} 1}, S_{\mathrm{c} 2}$, and $S_{\mathrm{c} 3}$ are functions of the depth of the layers $y_{1}, y_{2}$, and $y_{3}$, which may vary according to the following geometrical and static conditions:

$$
\begin{gathered}
y_{1}+y_{2}+y_{3}=h, \\
-f_{\mathrm{cm}} \leq \sigma_{\mathrm{c} i} \leq 0, \\
-f_{\mathrm{ym}} \leq \sigma_{\mathrm{s} i} \leq f_{\mathrm{ym}}, \\
\sigma_{\mathrm{p} 0} \leq \Delta \sigma_{\mathrm{p}} \leq f_{\mathrm{yp}}, \\
\sigma_{\mathrm{cw}} \leq \eta f_{\mathrm{cm}}, \\
V_{\mathrm{R}}=\min \left(V_{\mathrm{Rc}} ; V_{\mathrm{Rs}}\right) .
\end{gathered}
$$

The effectiveness factor $\eta$, introduced to take into account the degradation of axial compressive strength of concrete strut due to the transversal tensile strain, was assumed equal to $1 / 2$ [26].

The best outcome of the mathematical model was given by a linear programming method that allows to evaluate both the depth of the layers $\left(y_{1}, y_{2}, y_{3}\right)$, the $\cot \theta$, and all stresses $\left(\sigma_{\mathrm{c} i}, \Delta \sigma_{\mathrm{p}}, \sigma_{\mathrm{s} i}\right)$, by maximizing the element resisting actions in the respect of the ultimate boundary conditions of material strength and the geometrical restrains of the layer sizes. 


\section{Upgrading of the Model to the Case of Corroded RC and PC Beams}

The previous described model was modified according to the effect of corrosion both on concrete and steel. With this purpose, the degradation of the bearing capacity of cracked concrete near a corroding rebar was modeled following the strategy suggested by Coronelli and Gambarova [10].

In detail, the cylindrical compressive strength of concrete may be evaluated by means of the following:

$$
f_{\mathrm{cm}}^{*}=\frac{f_{\mathrm{cm}}}{1+K \varepsilon_{1} / \varepsilon_{\mathrm{c} 0}},
$$

where $K$ is the coefficient related to bar roughness and diameter assumed equal to $0.1, \varepsilon_{\mathrm{c} 0}$ is the strain at the peak compressive stress $f_{\mathrm{cm}}$, and $\varepsilon_{1}$ is the average tensile strain in the cracked concrete at right angles to the direction of the applied compression.

The value $\varepsilon_{1}$ can be evaluated by means of the following equation:

$$
\varepsilon_{1}=\frac{b_{\mathrm{f}}-b_{\mathrm{w}}}{b_{\mathrm{w}}},
$$

where $b_{\mathrm{w}}$ is the section width without corrosion crack and $b_{\mathrm{f}}$ is the increased width when corrosion cracks occur. In order to give an estimation of the increase, the following equation could be used:

$$
b_{\mathrm{f}}-b_{\mathrm{w}}=n_{\mathrm{bars}} \cdot w_{\mathrm{cr}}
$$

where $n_{\text {bars }}$ is the number of bars in the compressed layer and $w_{\text {cr }}$ is the total crack width for a given corrosion level that can be evaluated [27]:

$$
w_{\mathrm{cr}}=\sum_{i} u_{i, \mathrm{corr}}=2 \pi\left(u_{\mathrm{rs}}-1\right) \cdot X
$$

where $u_{\mathrm{rs}}$ is the ratio volumetric expansion of the oxides, $X$ is the corrosion depth, and $u_{i, \text { corr }}$ is the opening of the single crack. According to Molina et al. [27], $u_{\mathrm{rs}}$ was taken equal to 2 .

The stress-strain law for corroded steel was modified as suggested by Cairns et al. [16]. The equations are here reported and used in the model:

$$
\begin{aligned}
& f_{\mathrm{y}}=\left(1-\alpha_{\mathrm{y}} \cdot Q_{\mathrm{corr}}\right) f_{\mathrm{y} 0}, \\
& f_{\mathrm{u}}=\left(1-\alpha_{\mathrm{u}} \cdot Q_{\mathrm{corr}}\right) f_{\mathrm{u} 0}, \\
& \varepsilon_{\mathrm{u}}=\left(1-\alpha_{1} \cdot Q_{\mathrm{corr}}\right) \varepsilon_{0},
\end{aligned}
$$

where $f_{\mathrm{y}}, f_{\mathrm{u}}$, and $\varepsilon_{\mathrm{u}}$ represent yield strength, ultimate tensile strength, and elongation corresponding to ultimate strength after corrosion; $f_{\mathrm{y} 0}, f_{\mathrm{u} 0}$, and $\varepsilon_{0}$ represent yield strength, ultimate strength, and elongation of the noncorroded bar, respectively; and $Q_{\text {corr }}$ is the corrosion degree whereas $\alpha_{\mathrm{y}}=0.017, \alpha_{\mathrm{u}}=0.018$, and $\alpha_{1}=0.06$ are empirical coefficients [16].

\section{Validation of the Theoretical Model with Experimental Results}

The ability of the adapted model to reproduce the behavior response of corroded $\mathrm{RC}$ and $\mathrm{PC}$ beams under transversal loads was validated by comparing the numerical results to the strength values obtained by means of failure tests performed on many specimens having different geometrical setup and subjected to corrosion, available in the literature $[6-8,28]$.

In the following, the tests reported in the literature used for the validation are introduced and described.

4.1. RC Corroded Specimens. In the literature, several test campaigns carried out on corroded beams are available. Unfortunately, most of them are on structural elements which fail in pure bending. The database of experimental tests on corroded beams herein collected contains also specimens that reached a brittle failure for shear.

In Figure 2, the geometry, reinforcement arrangement, and location of corrosion for the specimens tested by (a) Rodriguez et al. [6], (b) El Maaddawy et al. [7], (c) Zhu and François [8], and (d) Youn and Kim [14] are shown. The corroded reinforcement is highlighted with a brownish color and with a different thickness.

4.1.1. Rodriguez et al. The test results presented by Rodriguez et al. [6] were carried out on specimens subjected to electrochemical corrosion to study the structural behavior of structural elements with corroded rebars. The beams, having dimensions $150 \times 200 \times 2300 \mathrm{~mm}$, were designed with high longitudinal reinforcement ratio ( $4 \phi 12$ for tensile and $4 \phi 8$ for compressive) and with stirrup space close to $d / 2$ $(\phi 6 / 85 \mathrm{~mm}), d$ being the effective depth of the beam. Both corroded and noncorroded beams were tested up to failure, applying two symmetrical concentrated loads at $800 \mathrm{~mm}$ from the supports. All reinforcements were corroded: longitudinal bottom (tensile) and top (compressive) rebars, and also stirrups (Figure 2(a)).

As shown in Table 1, where the main results are summarized both in terms of service/ultimate load and average attack penetration of reinforcement, the rebar cross section decreased, and the concrete cracking $(w)$ produced by corrosion at top and bottom rebars and also stirrups can justify the observed behavior. Most of the specimens reach the failure by concrete crushing, and in some cases, the yield stress of bottom rebars was not reached due to the deterioration of compressive face of the beam caused by corrosion of top rebars. Moreover, the corrosion of stirrups led to shear failure for beam 315 and to shear-flexure crisis for beam 316 [6].

4.1.2. El Maaddawy et al. An experimental study was carried out by El Maaddawy et al. [7] to investigate the combined effect of corrosion and sustained loads on the structural performance of RC beams. 


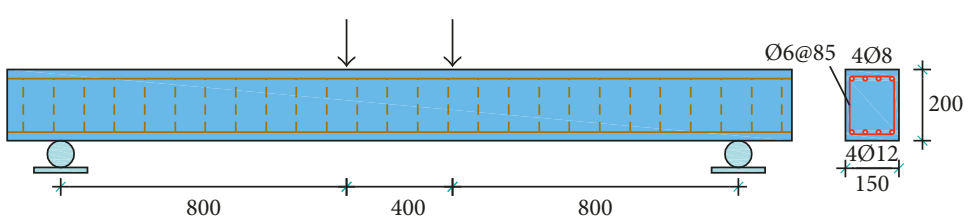

(a)

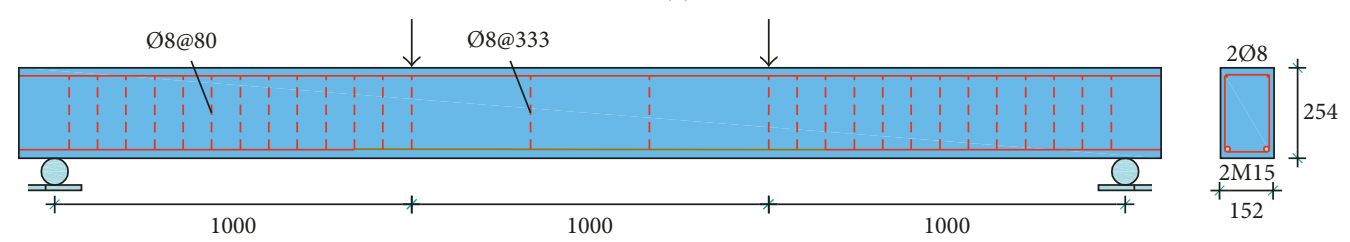

(b)

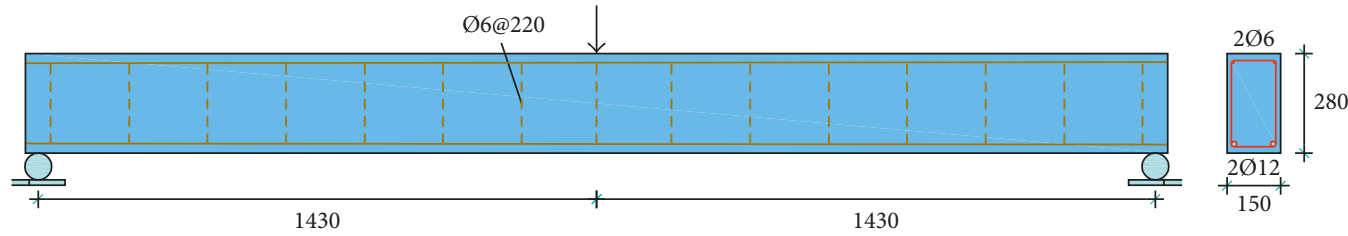

(c)

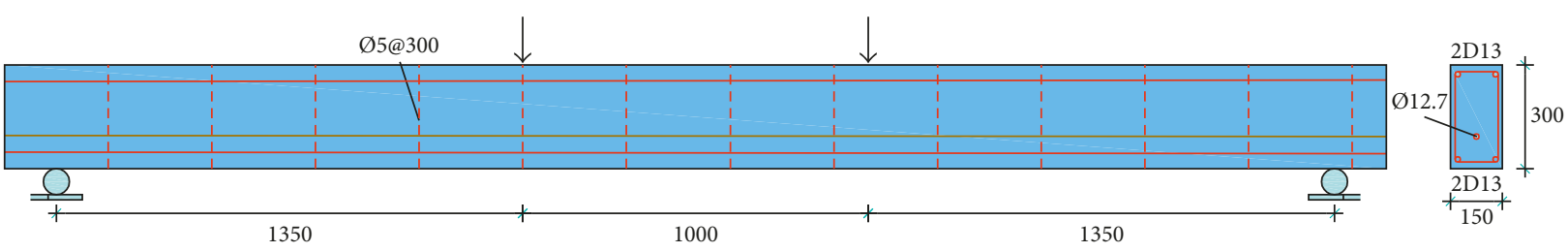

(d)

FIgURE 2: Geometry, reinforcement arrangement, and location of corrosion for the specimens tested by (a) Rodriguez et al. [6], (b) El Maaddawy et al. [7], (c) Zhu and François [8], and (d) Youn and Kim [14].

Table 1: Data of specimens tested by Rodriguez et al. [6].

\begin{tabular}{|c|c|c|c|c|c|c|c|c|c|}
\hline \multirow[b]{2}{*}{ Code } & \multirow[b]{2}{*}{$\begin{array}{c}\text { Days } \\
(\#)\end{array}$} & \multicolumn{3}{|c|}{ Bars' attack penetration } & \multicolumn{2}{|c|}{ Service load } & \multicolumn{3}{|c|}{ Ultimate load } \\
\hline & & $\begin{array}{l}\text { Tensile } \\
(\mathrm{mm})\end{array}$ & $\begin{array}{l}\text { Compressive } \\
(\mathrm{mm})\end{array}$ & $\begin{array}{l}\text { Stirrups } \\
(\mathrm{mm})\end{array}$ & $\begin{array}{c}\delta \\
(\mathrm{mm})\end{array}$ & $\begin{array}{c}w \\
(\mathrm{~mm})\end{array}$ & $\begin{array}{l}\text { Failure } \\
(\#)\end{array}$ & $\begin{array}{c}V \\
(\mathrm{kN})\end{array}$ & $\begin{array}{c}M \\
(\mathrm{kNm})\end{array}$ \\
\hline 311 & 0 & 0 & 0 & 0 & 5.3 & 0.2 & 2 & 52.3 & 38.1 \\
\hline 312 & 0 & 0 & 0 & 0 & 5.5 & 0.2 & 2 & 53.2 & 38.8 \\
\hline 313 & 111 & 0.3 & 0.2 & 0.35 & 5.5 & 0.2 & 2 & 38.7 & 28.2 \\
\hline 314 & 128 & 0.48 & 0.26 & 0.5 & 5.5 & 0.2 & 2 & 39 & 28.5 \\
\hline 316 & 164 & 0.42 & 0.37 & 5.9 & 5.9 & 0.3 & 2 & 37.7 & 27.5 \\
\hline 315 & 190 & 0.51 & 0.34 & 0.63 & 7.7 & 0.3 & 3 & 27.7 & 20.2 \\
\hline
\end{tabular}

They tested nine beams, having size $152 \times 254 \times 3200 \mathrm{~mm}$. One beam was tested as a sound whereas eight beams $(\mathrm{CN}$ and CS) were exposed to accelerated corrosion for up to 310 days using an impressed current technique.

Moreover, four of the nine beams were corroded under a sustained load equal to approximately $60 \%$ of the yield load of the virgin beam (CS specimens). The flexural reinforcement of specimens consisted of two number 15 deformed steel rebars for tensile and $2 \phi 8 \mathrm{~mm}$ for compressive. The transversal reinforcement consisted of stirrups $\phi 8 / 80 \mathrm{~mm}$ with a $25 \mathrm{~mm}$ clear cover $(c)$ in the shear span and $\phi 8 / 333 \mathrm{~mm}$ in the constant bending moment region of the beam (Figure 2(b)).
In this campaign, the corrosion was concentrated to tensile steel rebars placed in the middle of the specimen. However, the induced current was uniformly applied to the steel rebars, but only in the central part of the beam. The formation of pitting corrosion on the surface of the steel bars for both loaded and unloaded specimens was observed [7].

Table 2 summarizes the main results of tests, both in terms of yield/ultimate capacity and average attack penetration of tensile reinforcement. Test results of the $\mathrm{CN}$ specimens showed that corrosion of the steel rebar had almost no effect on the yield capacity. By contrast, the beams loaded during corrosion exposure (CS) slightly increased the reductions in the yield load and in the ultimate, respectively [7]. 
TABLE 2: Data of specimens tested by El Maaddawy et al. [7].

\begin{tabular}{|c|c|c|c|c|c|c|c|c|}
\hline \multirow{2}{*}{ Code } & \multirow{2}{*}{$\begin{array}{c}\text { Mass } \\
\text { loss (\%) }\end{array}$} & \multirow{2}{*}{$\begin{array}{l}\text { Bars' attack } \\
\text { penetration } \\
\text { Tensile }(\mathrm{mm})\end{array}$} & \multicolumn{3}{|c|}{ Yield capacity } & \multicolumn{3}{|c|}{ Ultimate capacity } \\
\hline & & & $P(\mathrm{~mm})$ & $\delta(\mathrm{mm})$ & $P(\mathrm{kN})$ & $\delta(\mathrm{mm})$ & $M(\mathrm{kNm})$ & $V(\mathrm{kN})$ \\
\hline Virgin & 0 & 0 & 67.2 & 15.6 & 75 & 73.3 & 37.5 & 37.5 \\
\hline CN-50 & 8.9 & 0.7 & 61.7 & 14.4 & 70.2 & 89 & 35.1 & 35.1 \\
\hline CN-110 & 14 & 1.1 & 57.4 & 13.9 & 66.8 & 78.4 & 33.4 & 33.4 \\
\hline $\mathrm{CN}-210$ & 22 & 1.8 & 50.7 & 13 & 60 & 62.4 & 30 & 30 \\
\hline $\mathrm{CN}-310$ & 31 & 2.7 & 44.1 & 11.7 & 53.3 & 59 & 31.2 & 31.2 \\
\hline CS-50 & 9.7 & 0.8 & 59.9 & 12.3 & 66.1 & 73.4 & 33 & 33 \\
\hline CS-110 & 15 & 1.2 & 55.1 & 8.9 & 64.6 & 85.9 & 32.3 & 32.3 \\
\hline CS-210 & 22 & 1.9 & 50.1 & 8.4 & 64.2 & 79.9 & 32.1 & 32.1 \\
\hline CS-310 & 30 & 2.6 & 46.1 & 7.4 & 56.9 & 66.8 & 28.4 & 28.4 \\
\hline
\end{tabular}

Table 3: Data of specimens tested by Zhu and François [8].

\begin{tabular}{lccccccc}
\hline Code & Years $(\#)$ & $\begin{array}{c}\text { Bars' attack penetration } \\
\text { Tensile }(\mathrm{mm})\end{array}$ & $P(\mathrm{~mm})$ & $\delta(\mathrm{mm})$ & $P(\mathrm{kN})$ & $\delta(\mathrm{mm})$ & \multicolumn{2}{c}{ Ultimate capacity } \\
& & 0 & 46 & 3.9 & 54.2 & 80.8 & 39.3 \\
B1T1 & 14 & 0 & 44.1 & 7.1 & 49.4 & 79.8 & 35.8 \\
B2T2 & 26 & 0 & 46 & 8.3 & 50.2 & 73.8 & 36.4 \\
B2T3 & 28 & 0.14 & 37 & 5.3 & 42.5 & 23 & 30.8 \\
B1Cl1 & 14 & 0.29 & 28.2 & 4 & 37 & 37 & 24.7 \\
B2Cl1 & 23 & 0.34 & 30 & 6.3 & 37.1 & 39.4 & 26.1 \\
B2Cl2 & 26 & 0.37 & 26 & 3.1 & 30.7 & 21 & 26.9 \\
B2Cl3 & 28 & & & & & 18.5 \\
\hline
\end{tabular}

4.1.3. Zhu and François. Zhu and François [8] presented an experimental work to investigate the influence of chloride corrosion of the rebars on the residual structural performance of RC beams. A mechanical experiment was conducted with a three-point loading system on three uncorroded and four corroded beams that were exposed to a chloride environment for 14, 23, 26, and 28 years. The specimens were cast with dimensions $150 \times 280 \times 3000 \mathrm{~mm}$ and longitudinal reinforced with $2 \phi 12$ for tensile and $2 \phi 6$ for compressive. The shear reinforcement was provided with stirrups $\phi 6 / 220 \mathrm{~mm}$ (Figure 2(c)).

The specimens reached the failure with the yielding of tensile rebars or premature crushing of concrete in compression. In detail, the beam $\mathrm{B} 2 \mathrm{Cl} 3$ failed with considerable spalling and even delamination of the concrete cover at the tensile section in the middle of the specimen [8].

Table 3 summarizes the main results of tests, both in terms of yield/ultimate capacity and average attack penetration of tensile reinforcement.

The average value of yield strength of the corroded rebars from the two specimens $\mathrm{B} 2 \mathrm{Cl} 2$ and $\mathrm{B} 2 \mathrm{Cl} 3$ was almost the same, which meant that the duration of corrosion had almost no impact on the yield strength of the corroded rebars. A similar result was observed also for the average value of ultimate strength [8].

\subsection{PC Corroded Specimens}

4.2.1. Youn and Kim. In the experimental study carried out by Youn and Kim [14], five beams (3700 mm span and $150 \times 300 \mathrm{~mm}$ cross section) were cast and four D13 ordinary rebars (two at the top and two at the bottom of the beam cross section) with $30 \mathrm{~mm}$ cover were used. Four members were post-tensioned with one seven-wire strand $(\phi=12.7 \mathrm{~mm})$ at a distance of $95 \mathrm{~mm}$ from the bottom of the beam and bonded with grout, while one was a RC beam without a strand (C1). The compressive concrete strength was $f_{\mathrm{cm}}=31 \mathrm{MPa}$; the yield strength of ordinary rebar was $f_{\mathrm{ym}}=400 \mathrm{MPa}$; and the mechanical properties of strand were $f_{\text {yp }}=1559 \mathrm{MPa}$ and $f_{\text {up }}=1834 \mathrm{MPa}$, respectively. The specimens were loaded with four points scheme test, adopting a shear span $a=1350 \mathrm{~mm}$ (Figure 2(d)). During the load tests, the acoustic emission technique was used to detect other wire failures [14].

The authors analyzed two different factors: the prestressing force level and the loss of strand area resulting from artificial corrosion. To perform artificial corrosion in two of the beams, the tendon already tensioned and bonded with grout in the ducts was exposed in the midspan cross section by drilling a $25 \mathrm{~mm}$ hole in the hardened concrete. Three wires were exposed for beam PC2 and two wires for beam PC3 (Table 4). More details about the tests can be found in $[14,28]$.

\section{Numerical Application}

The analytical proposed procedure was used to perform some numerical analysis by means of an algorithm implemented using the Mathematica framework [29]. Firstly, a value of the axial force $N_{\mathrm{E}}=0$ is chosen in (3.1), the corresponding value of the flexural resistance in the absence of simultaneous shear action $M_{\mathrm{fl}}$ is evaluated assuming $V_{\mathrm{R}}=0$ by an optimization procedure that maximizes $M_{\mathrm{E}}$, according to (4). Then, once a value of flexural $M_{\mathrm{E}}$ is chosen in the range $\left[0-M_{\mathrm{fl}}\right]$, the shear strength is assumed as objective function to be maximized. 
Table 4: Data of specimens tested by Youn and Kim [14].

\begin{tabular}{lcccc}
\hline Code & Prestress & Cross section loss & Ultimate load & Ultimate flexural strength \\
& $P_{0}=0.7 A_{\mathrm{p}} f_{\mathrm{pu}}(\%)$ & $A_{\mathrm{p}}(\%)$ & $P(\mathrm{kN})$ & 46 \\
\hline C1 & - & - & 67.5 & 31 \\
PC1 & 5 & 0 & 66.1 & 45.6 \\
PC2 & 60 & $10-30$ & 58.9 & 44.6 \\
PC3 & 78 & 30 & 82.5 & 39.8 \\
PC4 & 76 & 0 & 55.7 \\
\hline
\end{tabular}

Moreover, the concrete strength for uniaxial longitudinal stresses $f_{\mathrm{cd} 1}$ was evaluated neglecting the safety coefficient $\left(f_{\mathrm{cd} 1}=f_{\mathrm{cm}}\right)$, while for stresses in presence of transverse load, the concrete strength $f_{\mathrm{cd} 2}$ was calculated as proposed by the Italian code [26], assuming an effectiveness shear factor equal to $1 / 2\left(f_{\mathrm{cd} 2}=0.5 f_{\mathrm{cm}}\right)$.

5.1. Rodriguez et al. The modeling of specimens tested by Rodriguez et al. [6] has taken into account the reduction of the material strength, as described in the previous section, and also of the rebar cross section of longitudinal and transversal reinforcement. Moreover, the authors provided the average and the maximum (pitting) attack penetration. Therefore, the residual rebar diameter $\left(\phi_{\mathrm{r}}\right)$ was estimated considering both the average value $(\mu)$ of attack penetration and also a greater value as function of pitting using the scatter $(\sigma)$. The following equation was adopted to estimate the diameter of corroded rebar:

$$
\phi_{\mathrm{r}}=\phi-\alpha(\mu+k \sigma)
$$

where $\alpha$ is a coefficient which depends on the type of the attack and $k$ is a coefficient ranging between 0 and 0.25 . The interaction diagrams $M-V$ for all specimens tested by Rodriguez et al. [6] are shown in Figure 3.

Figure 3(a) shows that the proposed model is able to reproduce the experimental behavior of the noncorroded specimens (311 and 312). However, it should be noted that the analytical prediction is strongly influenced by the $k$ coefficient assumed. In most of cases, the intermediate value $k=0.15$ allows to obtain the best prediction, except for specimen 313 where $k=0.25$ is needed (Figure 3(b)). In all cases, the model was able to reproduce the interaction between shear and bending moment. The continuous gray line represents the linear relationship between the bending moment $M$ and shear $V$ for each test.

5.2. El Maaddawy et al. The experimental response of specimens tested by El Maaddawy et al. [7] was reproduced with the proposed analytical procedure. In this case, the tensile steel rebars were grade 60 , having yield $\left(f_{\mathrm{ym}}\right)$ and ultimate $\left(f_{\text {um }}\right)$ strengths of $450 \mathrm{MPa}$ and $585 \mathrm{MPa}$, respectively. Therefore, two numerical analyses for each specimen were performed, assuming as plastic limit of tensile steel stress the yield and the ultimate strength, respectively. The interaction diagrams $M-V$ for all specimens tested by El Maaddawy et al. [7] are shown in Figures 4 and 5.

For most of the specimens, the best analytical prediction was an intermediate value between the two curves obtained.
The mechanical characteristics of tensile steel rebar, specially its hardening behavior, as expected influenced the ultimate capacity of the specimen. Despite the high level of corrosion, the CN310 specimen showed a ultimate load value higher than the recorded value of $\mathrm{CN} 210$ beam and comparable with the result of $\mathrm{CN} 110$ beam.

It sounds unusual by a physical point of view and, as a consequence, the model predicted very conservative strength value with respect to the experimental result.

5.3. Zhu and François. As for the specimens tested by El Maaddawy et al. [7], the difference between the yield and ultimate value of tensile strength of steel rebar used by Zhu and François [8] in their beams was remarkable. In detail, the yield strength and the ultimate strength of steel were $560 \mathrm{MPa}$ and $620 \mathrm{MPa}$, respectively. Moreover, the authors estimated the average yield strength of tensile rebar by a statistical analysis, using a normal distribution.

Therefore, also for this group of tests, two numerical analyses for each specimen were performed, assuming as plastic limit of tensile steel stress the yield $\left(f_{\mathrm{ym}}\right)$ and the ultimate strength $\left(f_{\text {um }}\right)$, respectively. The interaction diagrams $M-V$ for all specimens tested by Zhu and François [8] are shown in Figure 6.

Apart from the noncorroded beams (B1T), also for this group of specimens, the proposed model was able to reproduce their ultimate behavior using an intermediate value for the plastic limit of tensile steel between the yield and the ultimate strength. The correct estimation of steel rebar strength at failure influenced the analytical prediction of the specimen load.

5.4. Youn and Kim. The $M-V$ curve domains obtained by the proposed model for the specimens tested by Youn and Kim [14] are shown in Figure 7.

The numerical results were conservative with respect to the experimental ones. It was probably due to the uneasy estimate of the strand stress at the time of the beam failure. This stress value was influenced by several variables, such as the loss of bond between strand and concrete due to corrosion. This remains a critical issue for corroded PC beams [30].

However, the proposed model provided a safe prediction of the load bearing capacity for both corroded and uncorroded beams. Moreover, the interaction diagrams $M-V$ provided by the analytical model showed the overall response behavior of the PC beams, considering the influence of axial force due to prestressing and the effects of corrosion. 

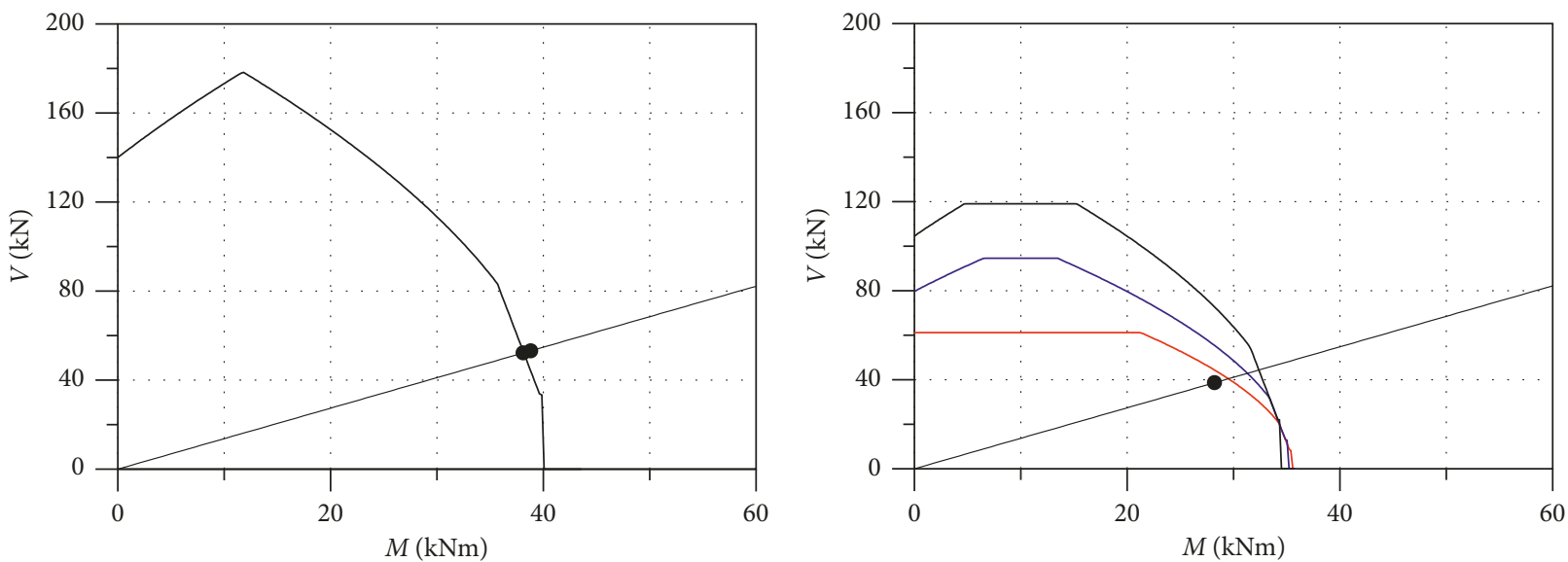

$-k=0$

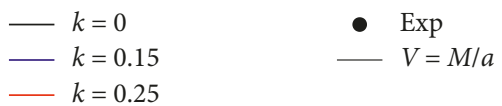

$\operatorname{Exp}$
$V=M / a$

(b)
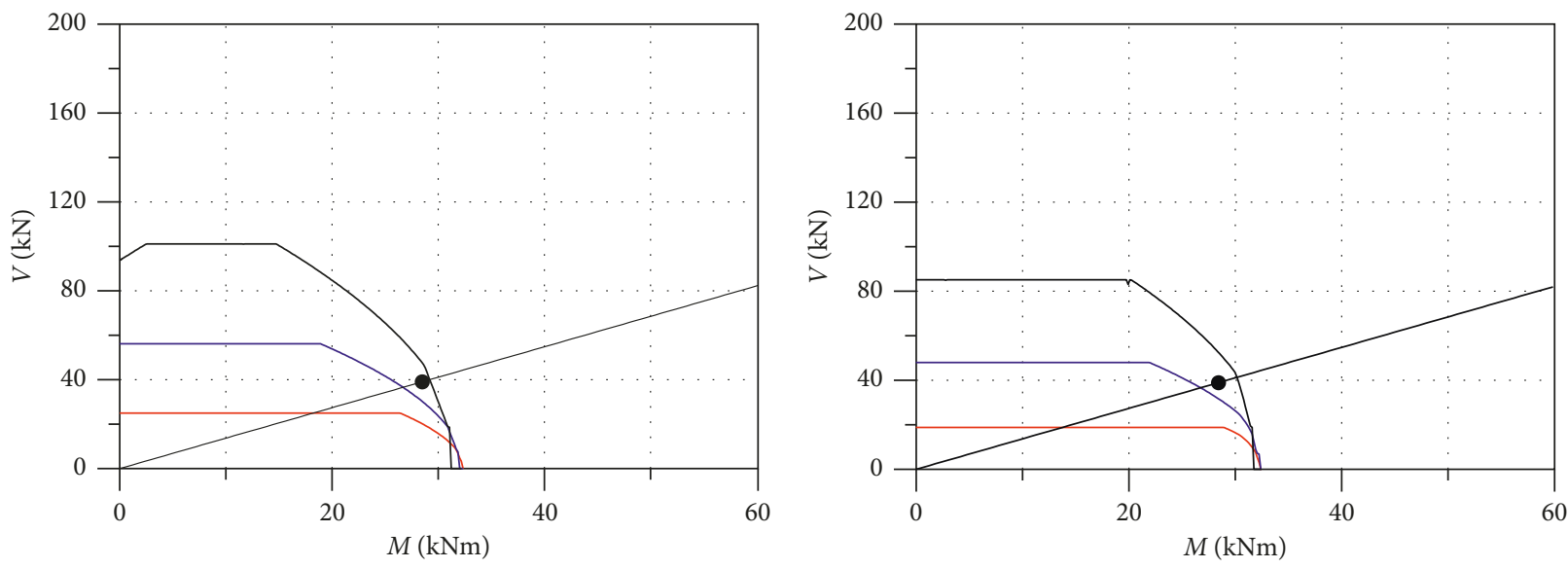

$\begin{aligned} k & =0 \\ k & =0.15 \\ k & =0.25\end{aligned}$

- $\operatorname{Exp}$

$\begin{aligned} k & =0 \\ -k & =0.15 \\ k & =0.25\end{aligned}$

- $\operatorname{Exp}$

$-V=M / a$

(c)

(d)
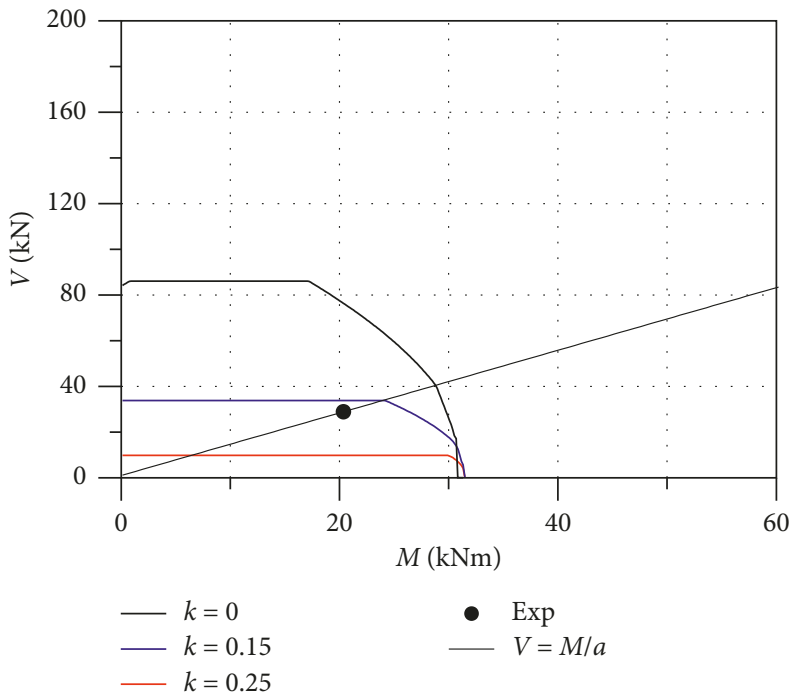

(e)

Figure 3: Interaction diagrams $M-V$ for all specimens tested by Rodriguez et al. [6]. (a) 311-2, (b) 313, (c) 314 , (d) 315 , and (e) 316 . 

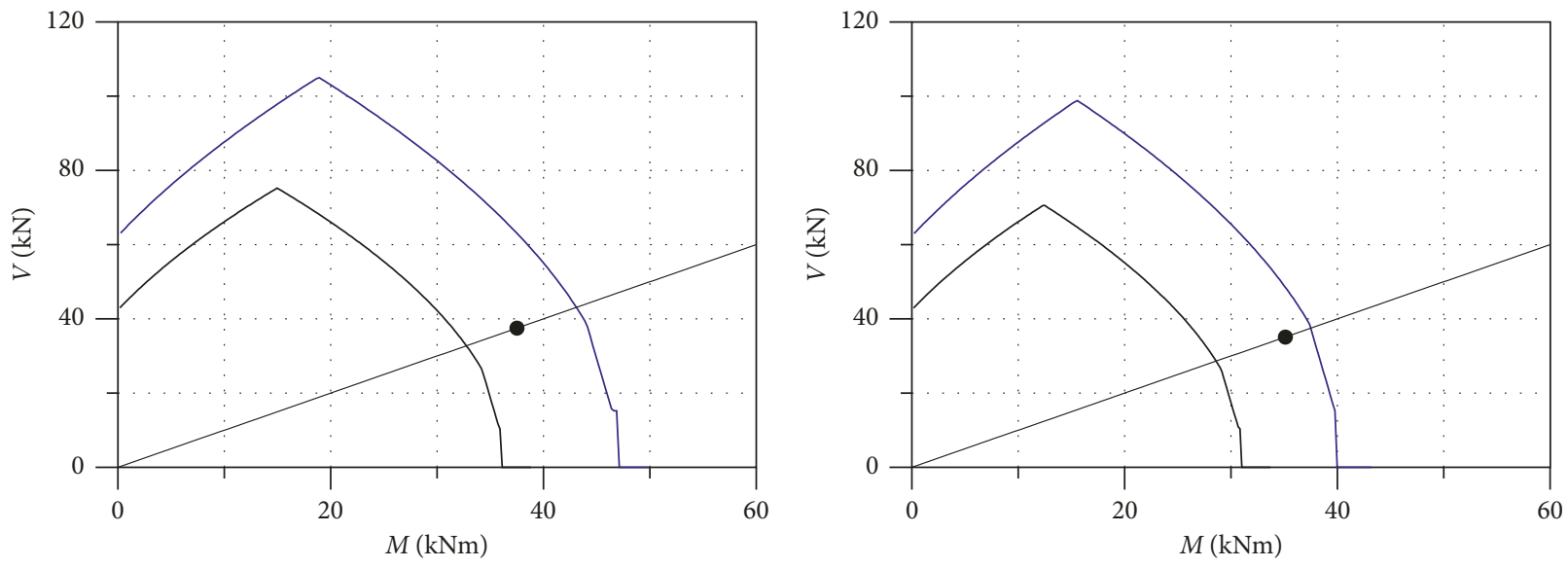

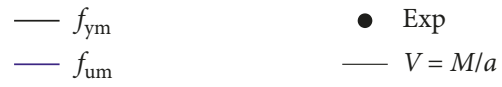

(a)

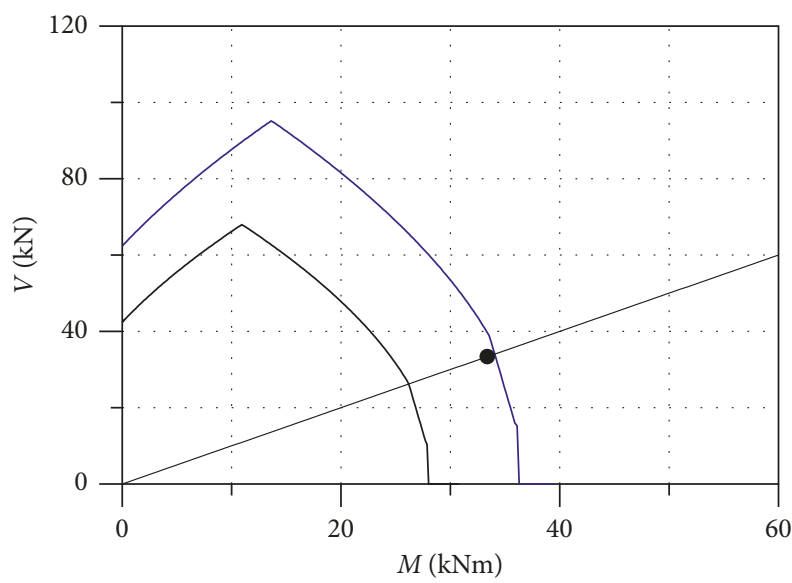

$-f_{\mathrm{ym}}$
- $\operatorname{Exp}$

$-V=M / a$

(c)

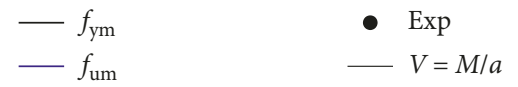

(b)

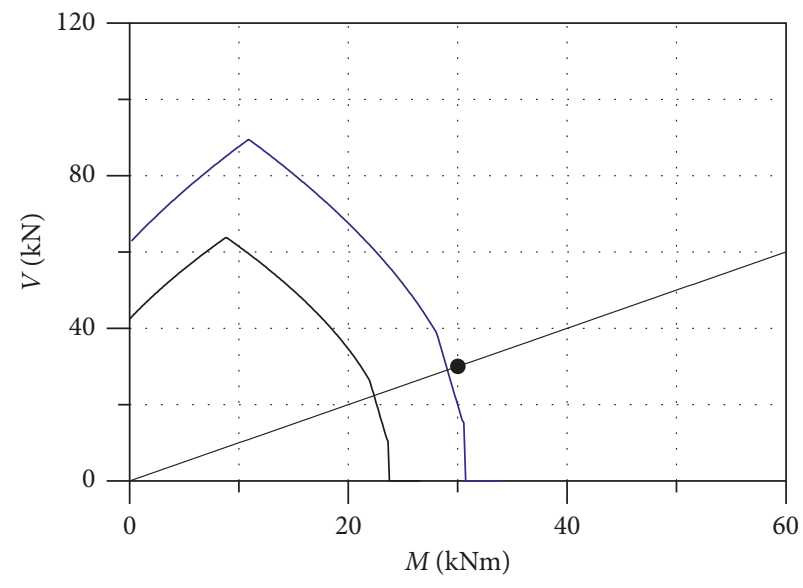

$-f_{\mathrm{ym}}$

(d)

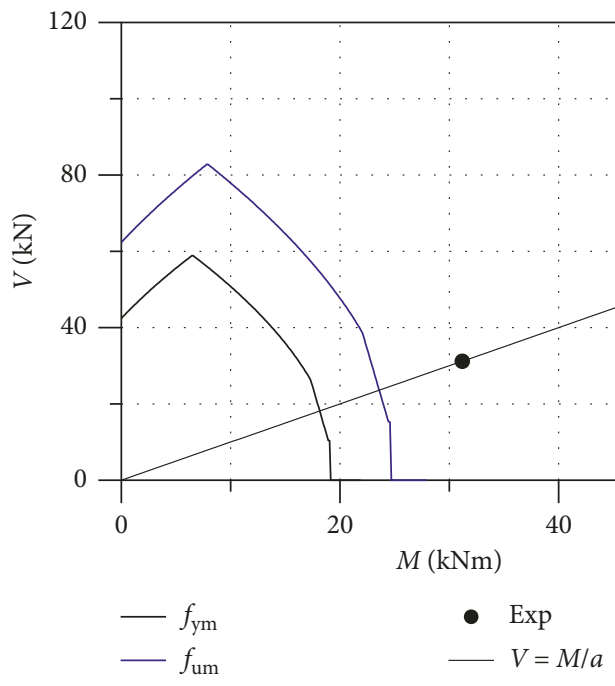

(e)

Figure 4: Interaction diagrams $M-V$ for $\mathrm{CN}$ specimens tested by El Maaddawy et al. [7]. (a) Virgin, (b) CN-50, (c) CN-110, (d) CN-210, and (e) CN-310. 


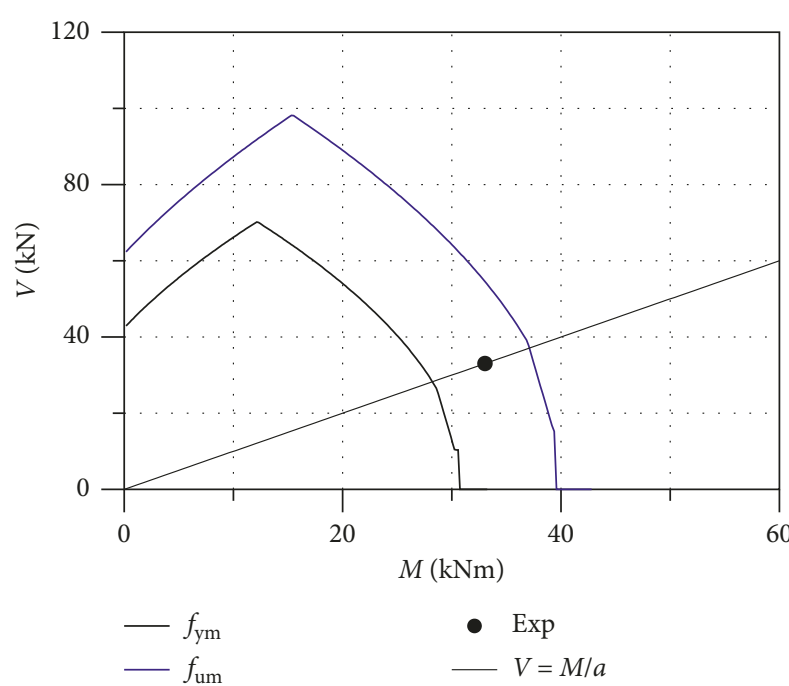

(a)

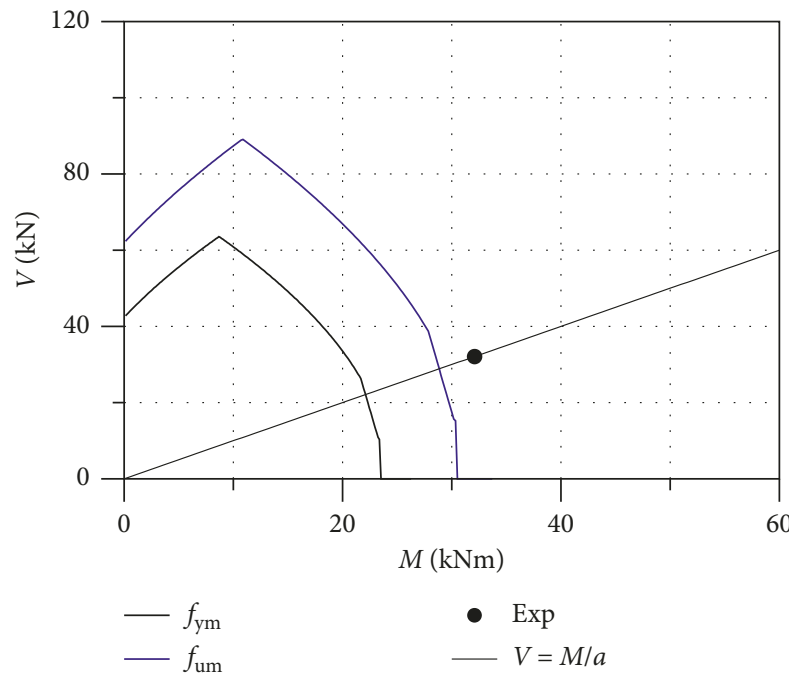

(c)

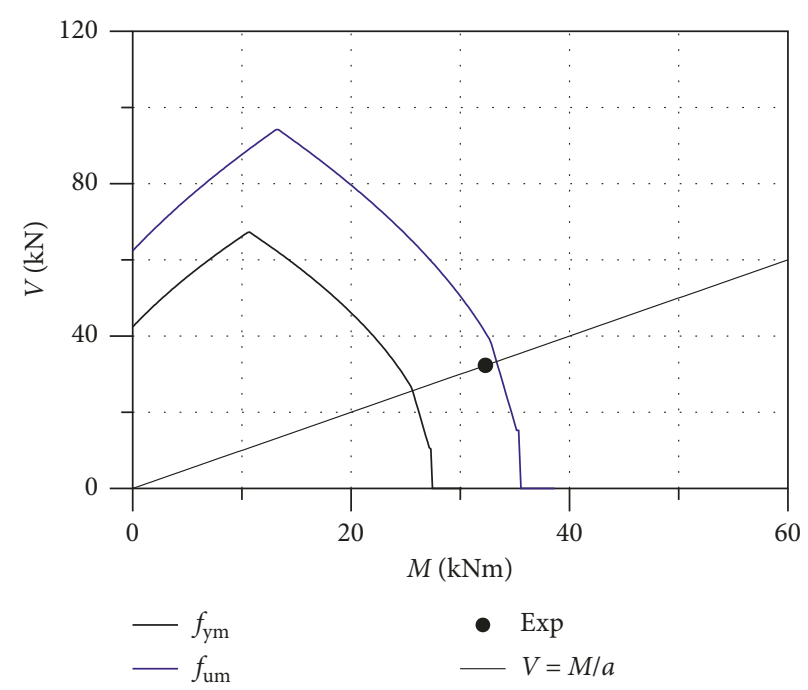

(b)

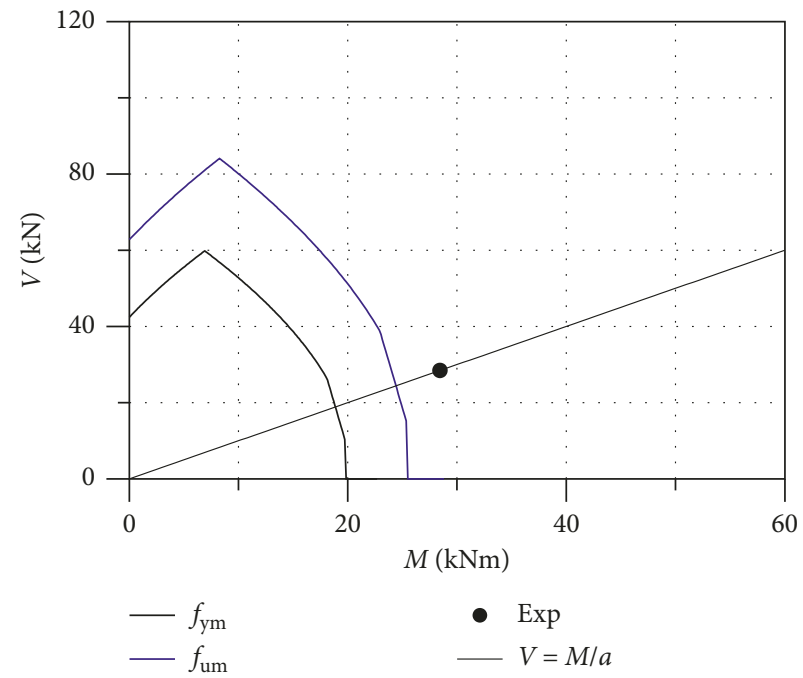

(d)

FIgURE 5: Interaction diagrams $M-V$ for CS specimens tested by El Maaddawy et al. [7]. (a) CS-50, (b) CS-110, (c) CS-210, and (d) CS-310.

\section{Conclusions}

In this work, a theoretical model based on equilibrium and ultimate strength theory for the analysis of corroded structure was employed.

The numerical formulation was able to take into account the interaction between shear and bending moment acting in the same cross section of RC and PC elements. The effects of the reduction of bearing capacity of concrete in compression and the reduction of steel rebar area together with the modification of the strength value for steel and concrete due to the corrosion were introduced. They were based on some linear degrading expressions suggested in the available literature.

The effect of corrosion is generally evaluated on statically determinate structure. In Fernandez et al.'s study [31], an experimental campaign on statically indeterminate structures in presence of corrosion of longitudinal reinforcement is reported. A valuable result is shown revealing a redistribution of actions in presence of corrosion and permanent loads.
Therefore actual structural performance in presence of corrosion should be referred to the resources hidden into the static scheme when redundancy of constrains is present as for framed structures.

The numerical results showed a good agreement with the experimental data taken from reliable experiences reported in the literature. From the results of the simulations of RC elements with ordinary steel, it was evident how the scatter, related to the global effect of corrosion on the structural capacity, increased with corrosion. This was clear from the comparison between experimental and analytical outcomes of Rodriguez et al. [6] where a different $k$ coefficient is suggested through the tests. Some differences were registered in few cases, especially for PC beams. They could be addressed to an even higher scatter of the phenomena of corrosion and to the difficulty in the estimation of the strand stress at failure.

The proposed model was able to provide the $M-V$ interaction diagrams for each specimen, highlighting how the 

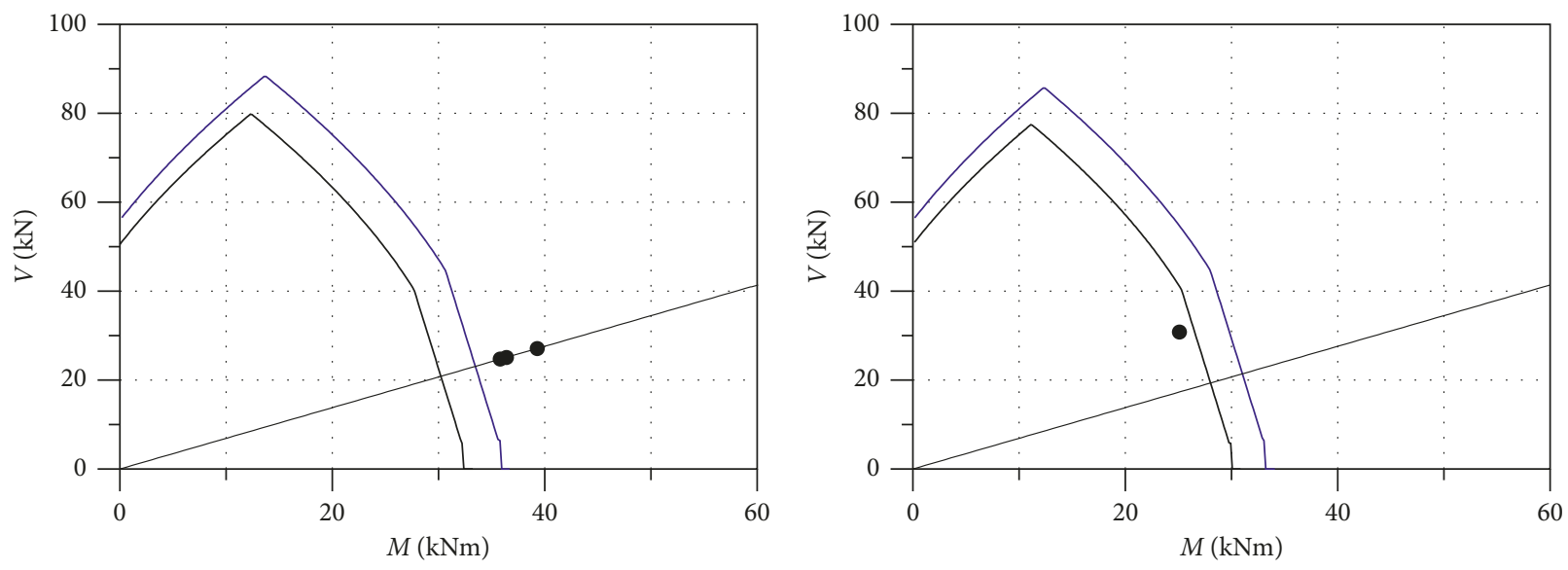

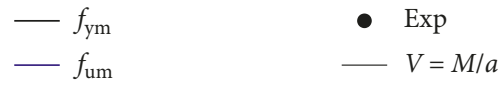

(a)

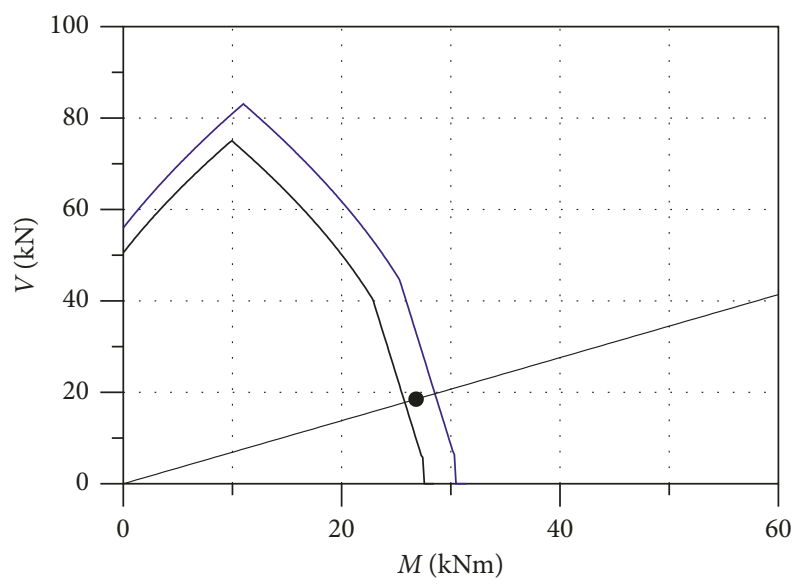

$-f_{\text {ym }}$
- $\operatorname{Exp}$

$-V=M / a$

(c)

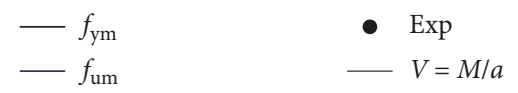

(b)

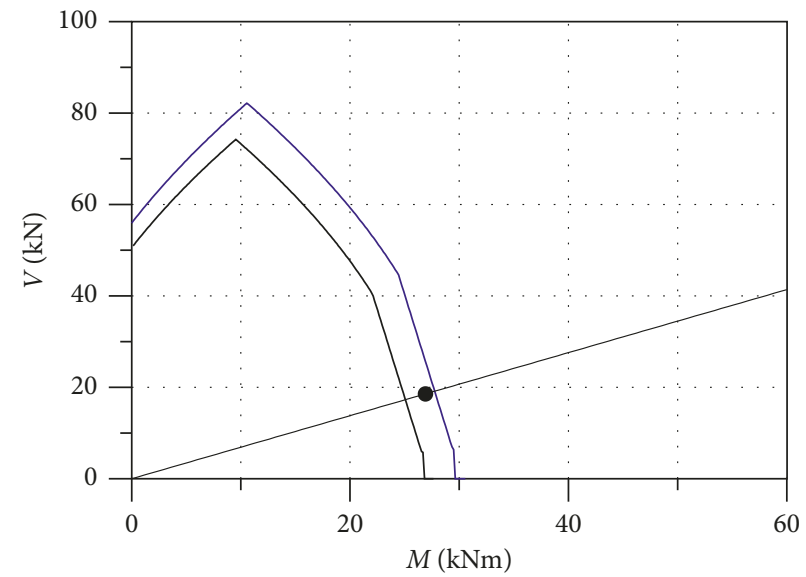

$-f_{\mathrm{ym}}$

- $\operatorname{Exp}$

(d)
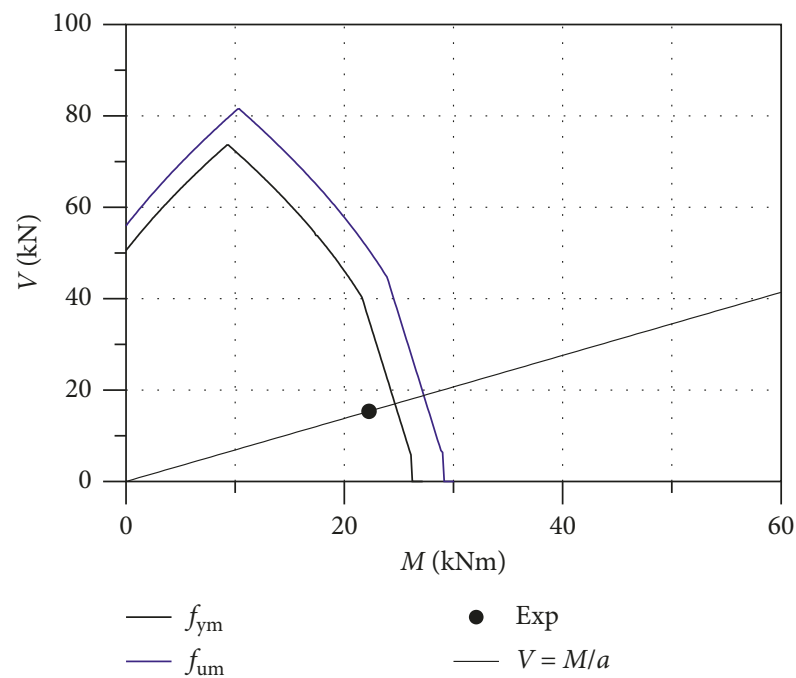

(e)

FIgURe 6: Interaction diagrams $M-V$ for all specimens tested by Zhu and François [8]. (a) B1T, (b) B1Cl1, (c) B2Cl1, (d) B2Cl2, and (e) $\mathrm{B} 2 \mathrm{Cl} 3$. 


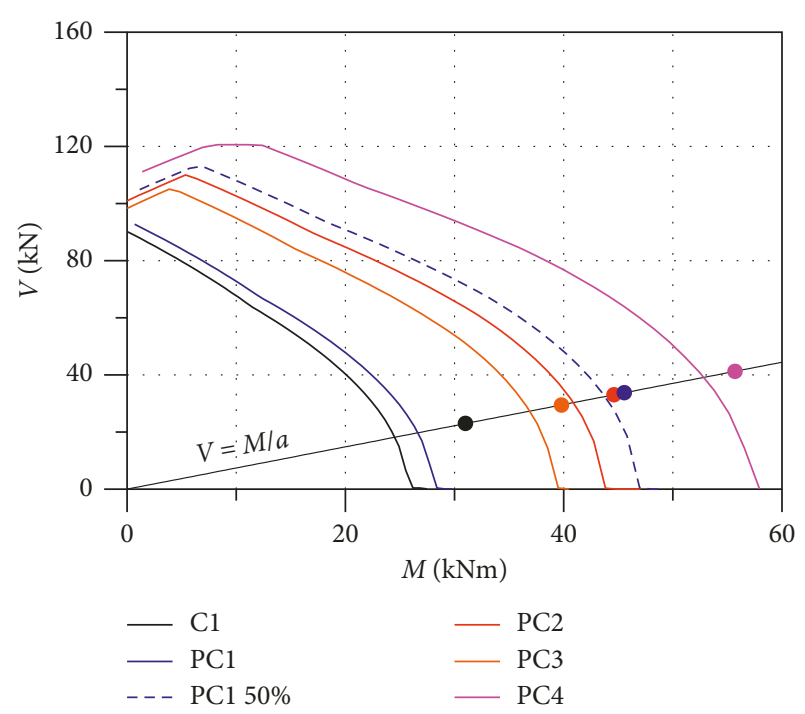

Figure 7: Interaction diagrams $M-V$ for all specimens tested by Youn and Kim [14].

strength domain changed along the axis of the beam. The influence of corrosion effects and axial force (for PC beams) was also recognized.

The model will be tested on a larger database when available in order to strengthen its reliability and improve its robustness on a scattered phenomenon like corrosion. Furthermore, it should be improved in order to take into account other effects of corrosion as the bond loss between steel and concrete.

\section{Data Availability}

The data used to support the findings of this study are available from the corresponding author upon request.

\section{Conflicts of Interest}

The Authors declare that this research fund (PRIN Grant $2015 \mathrm{HZ} 24 \mathrm{KH}$ ) does not lead to any conflicts of interest regarding the publication of this manuscript.

\section{Acknowledgments}

The financial support from the Italian Ministry of Education, University and Research (PRIN Grant 2015HZ24KH_- "Failure mechanisms caused by corrosive degrade and by lack of constructive details in the existing structures in reinforced concrete") is gratefully acknowledged. Nino Spinella wishes to express his personal gratitude to this research fund and also to the PRIN Grant 2015HZ24KH, through which a research fellow scholarship was awarded. A special acknowledgment goes also to Dr. A. Cesetti and Professor G. Mancini for their valuable contribution to the first stage of research [9].

\section{References}

[1] F. Tondolo, "Bond behaviour with reinforcement corrosion," Construction and Building Materials, vol. 93, pp. 926-932, 2015.
[2] G. Mancini and F. Tondolo, "Effect of bond degradation due to corrosion-a literature survey," Structural Concrete, vol. 15, no. 3, pp. 408-418, 2014.

[3] C. Jiang, Y. F. Wu, and M. J. Dai, "Degradation of steel-toconcrete bond due to corrosion," Construction and Building Materials, vol. 158, pp. 1073-1080, 2018.

[4] U. Nürnberger, "Corrosion induced failure mechanisms of prestressing steel," Materials and Corrosion, vol. 53, no. 8, pp. 591-601, 2002.

[5] P. Colajanni, A. Recupero, G. Ricciardi, and N. Spinella, "Failure by corrosion in PC bridges: a case history of a viaduct in Italy," International Journal of Structural Integrity, vol. 7, no. 2, pp. 181-193, 2016.

[6] J. Rodriguez, L. M. Ortega, and J. Casal, "Assessing structural conditions of concrete structures with corroded reinforcement," in Proceedings of the 4th International Conference on Concrete in the Service of Mankind, Concrete Repair Reabilitation and Protection, Dundee, UK, 1996.

[7] T. El Maaddawy, K. Soudki, and T. Topper, "Long-term performance of corrosion-damaged reinforced concrete beams," ACI Structural Journal, vol. 102, no. 5, pp. 649-656, 2005.

[8] W. Zhu and R. François, "Structural performance of RC beams in relation with the corroded period in chloride environment," Materials and Structures, vol. 48, no. 6, pp. 1757-1769, 2015.

[9] A. Cesetti, G. Mancini, A. Recupero, N. Spinella, and F. Tondolo, "Physical model for structural evaluation of R.C. beams in presence of corrosion," in Proceedings of the 4th International Conference on Concrete Repair, Rehabilitation and Retrofitting (ICCRRR-4), pp. 107-114, Leipzig, Germany, October 2015.

[10] D. Coronelli and P. Gambarova, "Structural assessment of corroded reinforced concrete beams: modeling guidelines," Journal of Structural Engineering, vol. 130, no. 8, pp. 12141224, 2004.

[11] K. Toongoenthong and K. Maekawa, "Multi-mechanical approach to structural performance assessment of corroded RC members in shear," Journal of Advanced Concrete Technology, vol. 3, no. 1, pp. 107-122, 2005.

[12] A. L. Presti, A. Recupero, and N. Spinella, "Influence of Rebar corrosion on RC frame push-over response," in Proceedings of the High Tech Concrete: Where Technology and Engineering Meet, pp. 2118-2126, Maastricht, The Netherlands, June 2017.

[13] D. Coronelli, A. Castel, N. A. Vu, and R. Francois, "Corroded post-tensioned beams with bonded tendons and wire failure," Engineering Structures, vol. 31, no. 8, pp. 1687-1697, 2009.

[14] S. G. Youn and E. K. Kim, "Deterioration of bonded posttensioned concrete bridges and research topics on the evaluation techniques in ISARC," in Proceedings of the JSCE-KSCE Joint Seminar Maintenance and Management Strategy of Infrastructures in Japan and Korea, Kusatsu, Japan, September 2006.

[15] Z. Rinaldi, S. Imperatore, and C. Valente, "Experimental evaluation of the flexural behavior of corroded P/C beams," Construction and Building Materials, vol. 24, no. 11, pp. 2267-2278, 2010.

[16] J. Cairns, G. Plizzari, Y. Du, D. W. Law, and C. Franzoni, "Mechanical properties of corrosion-damaged reinforcement," ACI Materials Journal, vol. 102, no. 4, pp. 256-264, 2005.

[17] D. G. Cavell and P. Waldron, "Parametric study of the residual strength of deteriorating simply-supported post-tensioned concrete bridges," Structures Buildings, vol. 146, no. 4, pp. 341-352, 2001. 
[18] L. Giordano, G. Mancini, and F. Tondolo, "Reinforced concrete members subjected to cyclic tension and corrosion," Journal of Advanced Concrete Technology, vol. 9, no. 3, pp. 277-285, 2011.

[19] I. Khan, R. François, and A. Castel, "Experimental and analytical study of corroded shear-critical reinforced concrete beams," Materials and Structures, vol. 47, no. 9, pp. 14671481, 2014.

[20] A. K. El-Sayed, "Shear capacity assessment of reinforced concrete beams with corroded stirrups," Construction and Building Materials, vol. 134, pp. 176-184, 2017.

[21] FIB (Federation International du Béton), Fib Bulletin No. 10Bond of Reinforcement in Concrete, FIB, Lausanne, Switzerland, 2000, ISBN 978-2-88394-050-5.

[22] R. Azam and K. Soudki, "Structural performance of shearcritical RC deep beams with corroded longitudinal steel reinforcement," Cement and Concrete Composites, vol. 34, no. 8, pp. 946-957, 2012.

[23] A. Recupero, A. D'Aveni, and A. Ghersi, "Bending momentShear force interaction domains for prestressed concrete beams," Journal of Structural Engineering, vol. 131, no. 9, pp. 1413-1421, 2005.

[24] P. Colajanni, A. Recupero, and N. Spinella, "Shear strength degradation due to flexural ductility demand in circular R.C. columns," Bulletin of Earthquake Engineering, vol. 13, no. 6, pp. 1795-1807, 2015.

[25] P. Colajanni, A. Recupero, and N. Spinella, "Design procedure for prestressed concrete beams," Computers and Concrete, vol. 13, no. 2, pp. 235-253, 2014.

[26] NTC08 C.E., Istruzioni per l'Applicazione delle Norme Tecniche per le Costruzioni di Cui al D.M. 14 Gennaio 2008, Ministero delle Infrastructure, Rome, Italy, 2008, in Italian.

[27] F. J. Molina, C. Alonso, and C. Andrade, "Cover cracking as a function of rebar corrosion. Part II-numerical model," Materials and Structures, vol. 26, no. 9, pp. 532-548, 1993.

[28] A. Castel, D. Coronelli, and R. Francois, "Response of corroded prestressed beams with bonded strands," Proceedings of the Institution of Civil Engineers-Structures and Buildings, vol. 165, no. 5, pp. 233-244, 2012.

[29] Wolfram Research, Inc., Mathematica, Wolfram Research, Inc., Champaign, IL, USA, 2008.

[30] S. M. R. Lopes and L. M. L. P. Simões, "Influence of corrosion on prestress strands," Canadian Journal of Civil Engineering, vol. 26, no. 6, pp. 782-788, 1999.

[31] I. Fernandez, M. F. Herrador, A. R. Marí, and J. M. Bairán, "Structural effects of steel reinforcement corrosion on statically indeterminate reinforced concrete members," Materials and Structures, vol. 49, no. 12, pp. 4959-4973, 2016. 


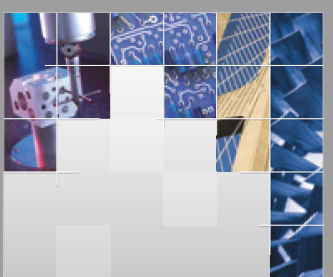

\section{Enfincering}
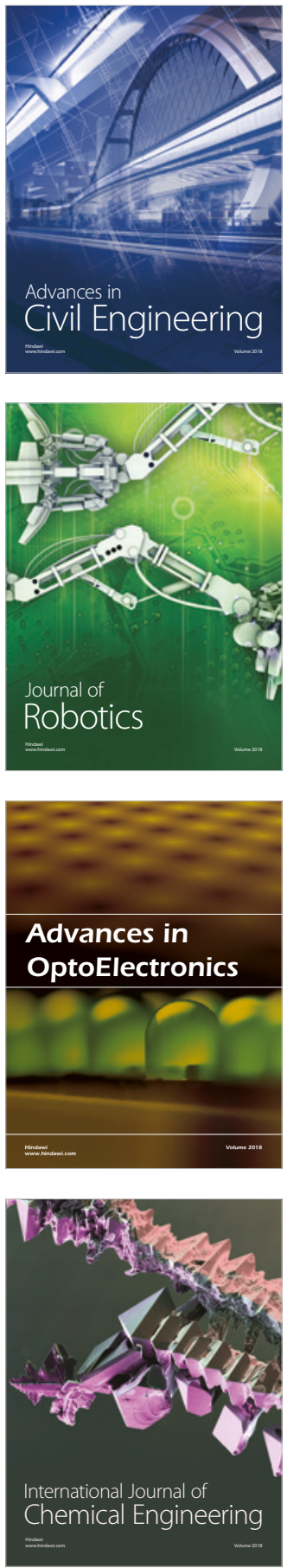

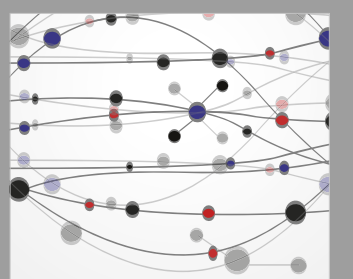

\section{Rotating \\ Machinery}

The Scientific World Journal

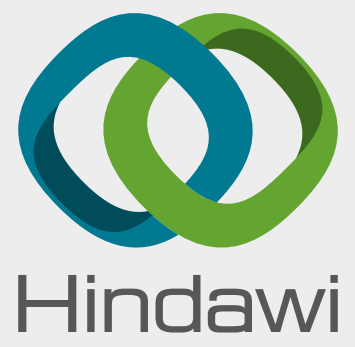

Submit your manuscripts at

www.hindawi.com
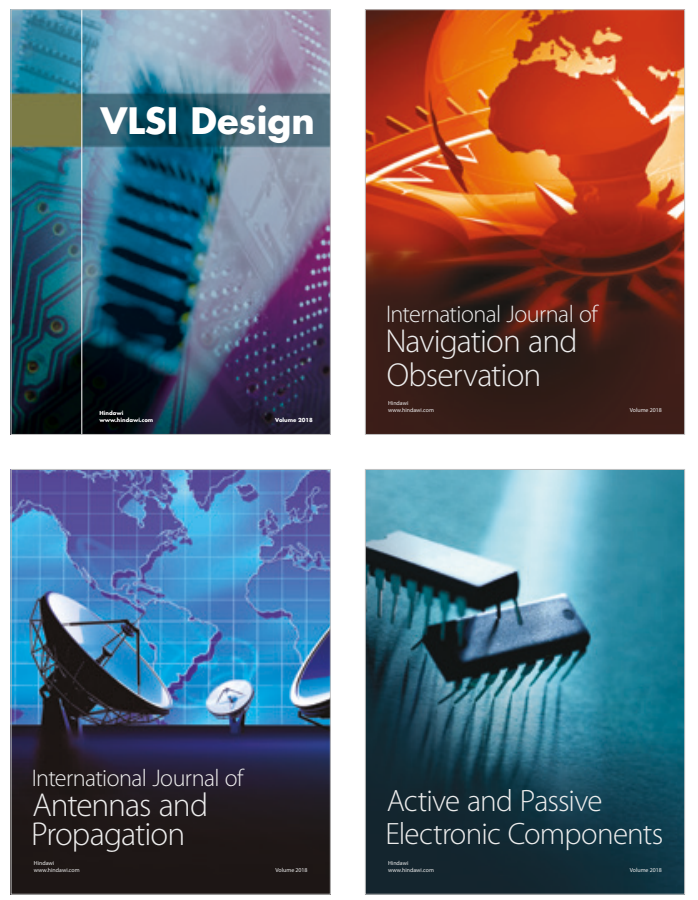
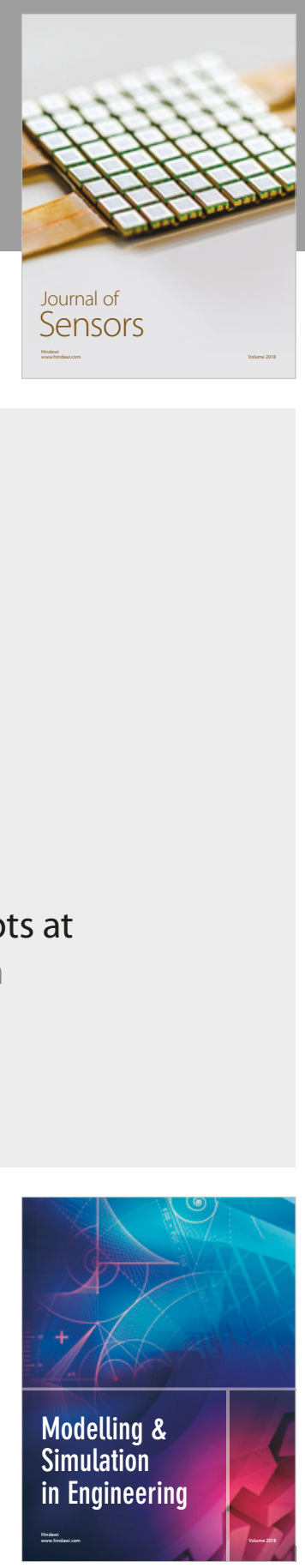

\section{Advances \\ Multimedia}
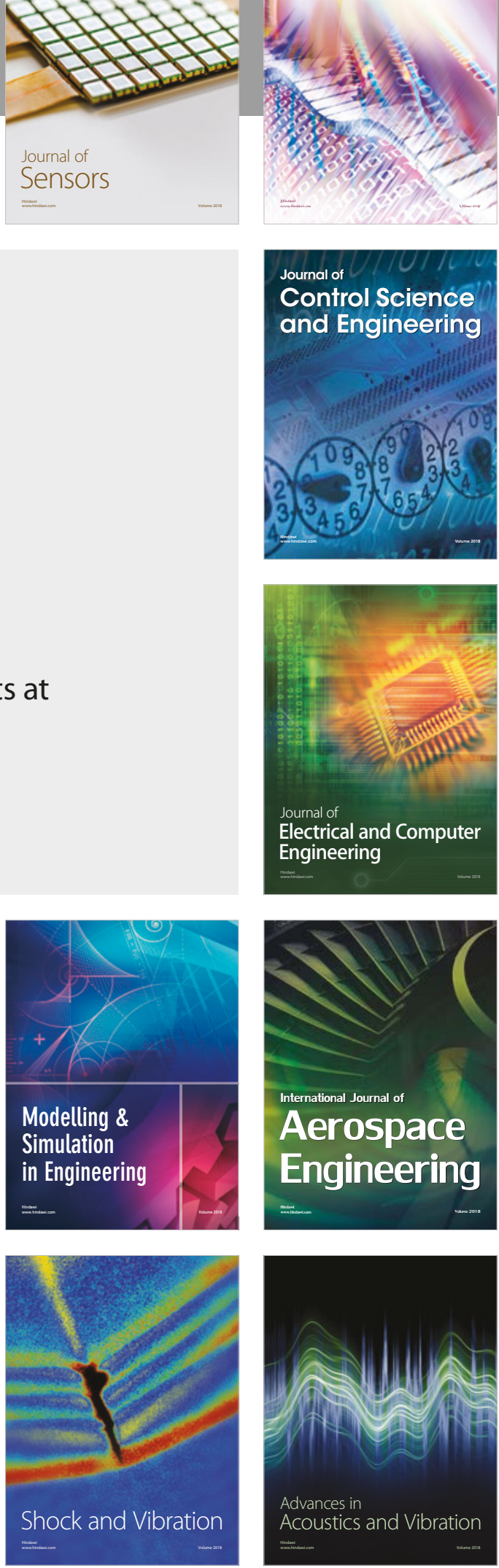